\title{
Multiple restriction fragment length polymorphisms at the GLUT2 locus: GLUT 2 haplotypes for genetic analysis of Type 2 (non-insulin-dependent) diabetes mellitus
}

\author{
P.Patel ${ }^{1,2}$, G. I.Bell ${ }^{3}$, J. T. E. Cook ${ }^{1}$, R. C. Turner ${ }^{1}$ and J.S. Wainscoat ${ }^{2}$ \\ Diabetes Research Laboratories, Nuffield Department of Clinical Medicine, Radcliffe Infirmary, \\ 2 Department of Haematology, John Radcliffe Hospital, Headington, Oxford, UK, and \\ ${ }^{3}$ Howard Hughes Medical Institute, University of Chicago, Chicago, Illinois, USA
}

\begin{abstract}
Summary. The liver/islet glucose transporter (GLUT2) is expressed in the liver and in the Beta cells of pancreatic islets and is a candidate gene for the inherited defect in Type 2 (non-insulin-dependent) diabetes mellitus. A series of restriction fragment length polymorphisms have been identified using a GLUT2 cDNA probe with five restriction enzymes in a British white Caucasian population. Five independent restriction fragment length polymorphisms detected by restriction enzymes EcoRI (two restriction fragment length polymorphisms termed EcoRI-1, EcoRI-2), TaqI (two restriction fragment length polymorphisms termed TaqI-1, TaqI-2), and BclI (BclI-2) were used to construct GLUT2 haplotypes. Significant linkage disequilibrium was observed between four polymorphic sites EcoRI-2, TaqI-1, TaqI-2 and
\end{abstract}

BclI-2 but linkage disequilibrium was not observed with EcoRI-1 polymorphic site and the other four sites. The frequencies of GLUT2 restriction fragment length polymorphisms and haplotypes in 50 Type 2 diabetic subjects and 50 non-diabetic control subjects show no significant differences suggesting that it is unlikely that there is a single major defect of this gene contributing to the inherited susceptibility to Type 2 diabetes in a Caucasian population.

Key words: Type 2 (non-insulin-dependent) diabetes mellitus, genetics, liver/islet glucose transporter gene, restriction fragment length polymorphism, population association study.
Genetic factors play a major role in the aetiology of Type 2 (non-insulin-dependent) diabetes mellitus, although the nature of the putative gene defect is unknown [1]. Both Beta-cell dysfunction and tissue insulin insensitivity are important in Type 2 diabetes. The recent characterisation by molecular cloning of the family of genes coding for glucose transporter proteins which facilitate the uptake of glucose into the cells has allowed us to study the possible involvement of the liver/islet glucose transporter (GLUT2) [2-4] in Type 2 diabetes. This glucose transporter is unique in that it is expressed in liver and in Beta cells of pancreatic islets and a defect of this gene could give rise to the two principle characteristics of Type 2 diabetes, namely insulin resistance and relative hypoinsulinaemia [5]. We have found several GLUT2 restriction fragment length polymorphisms (RFLPs) and have used these to construct a GLUT2 haplotype. The usefulness of this approach has been shown by work on beta-thalassaemia [6], cystic fibrosis [7] and phenylketonuria [8] where positive associations have been found between each of these diseases and particular haplotypes.

There has been one study showing no association between DNA polymorphisms at the GLUT2 locus and
Type 2 diabetes in American blacks [9]. This study did not detect polymorphisms at the GLUT 2 locus in whites and Pima Indians and claimed that the absence of these common polymorphisms in whites limited the ability to do population studies or linkage analysis. However, our study clearly shows that there are a number of polymorphisms at the GLUT2 locus in Caucasians and this finding has allowed us to evaluate the relationship between the GLUT2 DNA polymorphisms and haplotypes, and Type 2 diabetes. We do not find any positive associations between GLUT2 RFLPs and haplotypes, and Type 2 diabetes.

\section{Subjects and methods}

\section{Subjects}

The subjects included 98 unrelated British white Caucasian Type 2 diabetic subjects recruited from the Oxford U.K. Prospective Diabetes Study Clinic and 50 normoglycaemic volunteer control individuals of the same ethnic group. Individuals with Type 2 diabetes were diagnosed by following criteria, diabetes diagnosed by World 
Health Organisation criteria, and on therapy with oral hypoglycaemic agents, insulin or a specific diet. Fasting hyperglycaemia, with a fasting plasma glucose concentration $>6 \mathrm{mmol} / \mathrm{l}$ which is 3 SD above the mean of a normal population [10].

\section{Restriction endonuclease analysis}

Initial screening for DNA polymorphisms was performed in a panel of 19 unrelated Caucasian individuals using a 2.4 kilobase (kb) SalI insert of GLUT2 cDNA clone pGEM 4Z/HTL3 encoding the liver/islet glucose transporter gene [2].

DNA was extracted from peripheral blood by standard methods [11]. Digests were carried out with $5 \mu \mathrm{g}$ of DNA and a three- to fivefold excess of restriction endonuclease [Anglian Biotechnology, Colchester UK] for 4-16 h under conditions specified by the manufacturer. Digested DNA was separated by size on $0.8-1 \%$ agarose gels, denatured, neutralized and transferred to Hybond $\mathrm{N}$ membrane [Amersham International, Amersham, UK] by Southern blotting [12]. The filters were subsequently hybridised with a $\left[{ }^{32} \mathrm{p}\right] \mathrm{dCTP}$ labelled GLUT2 GEM 4Z/HTL3 probe by random primed DNA labelling [13] using a commercial kit [Boehringer Mannheim, London, UK]. Following hybridization the filters were washed and the bands visualized by autoradiography at $-70^{\circ} \mathrm{C}$ with intensifying screens.

\section{Statistical analysis}

The allelic frequencies of each RFLP and haplotype frequencies were compared in non-diabetic and Type 2 diabetic subjects and the results analysed by $\chi^{2}$ analysis. Linkage disequilibrium (non-random associations) between the GLUT2 RFLPs was performed by establishing haplotypes with each pair of RFLPs at one time and was assessed by the standardised disequilibrium statistic, $\Delta$ defined as:

$\Delta=\frac{a d-b c}{[(a+b)(c+d)(a+c)(b+d)]^{1 / 2}}$

Where $a, b, c$, and $d$ are frequencies of,,+++--+ and -- haplotypes, respectively [14] (" + "symbol refers to the presence of a restriction site and a "-" symbol refers to the absence of a restriction site). The calculated $\Delta$ values are used to test the null hypothesis of linkage disequilibrium $(\Delta=0)$ using $n \Delta^{2}\left(n=\right.$ sample size) as a $\chi^{2}$ variable with one degree of freedom.

\section{Results}

\section{Restriction fragment length polymorphisms}

DNA samples from 19 unrelated individuals were digested with restriction enzymes EcoRI, TaqI, BclI, SstI, PstI, PvuII, StuI, BamII, HindII, MspI, XbaI and AvaII. Eight DNA polymorphisms were observed, two previously described (EcoRI-1, EcoRI-2) [15] and six additional ones (PstI, BclI (two RFLPs termed BclI-1 and BcII-2), TaqI (two RFLPs termed TaqI-1 and TaqI-2) and SstI). Each polymorphism was confirmed by codominant inheritance in six nuclear families. The six additional polymorphisms include a PstI RFLP recognised by $3.6 \mathrm{~kb}$ and $3.7 \mathrm{~kb}$ alleles, BclI-1 RFLP recognised by $6.6 \mathrm{~kb}$ and $6.7 \mathrm{~kb}$ alleles, BclI-2 RFLP recognised by $4.1 \mathrm{~kb}, 3.8 \mathrm{~kb}$ and $7.9 \mathrm{~kb}$ alleles, SstI RFLP recognised by $4.4 \mathrm{~kb}$ and $4.5 \mathrm{~kb}$ alleles, TaqI- 1 RFLP recognised by $14 \mathrm{~kb}$ and $23 \mathrm{~kb}$ alleles and TaqI-2 RFLP recognised by $3.9 \mathrm{~kb}, 2.9 \mathrm{~kb}$ and $7.5 \mathrm{~kb}$ alleles (Fig. 1 ).

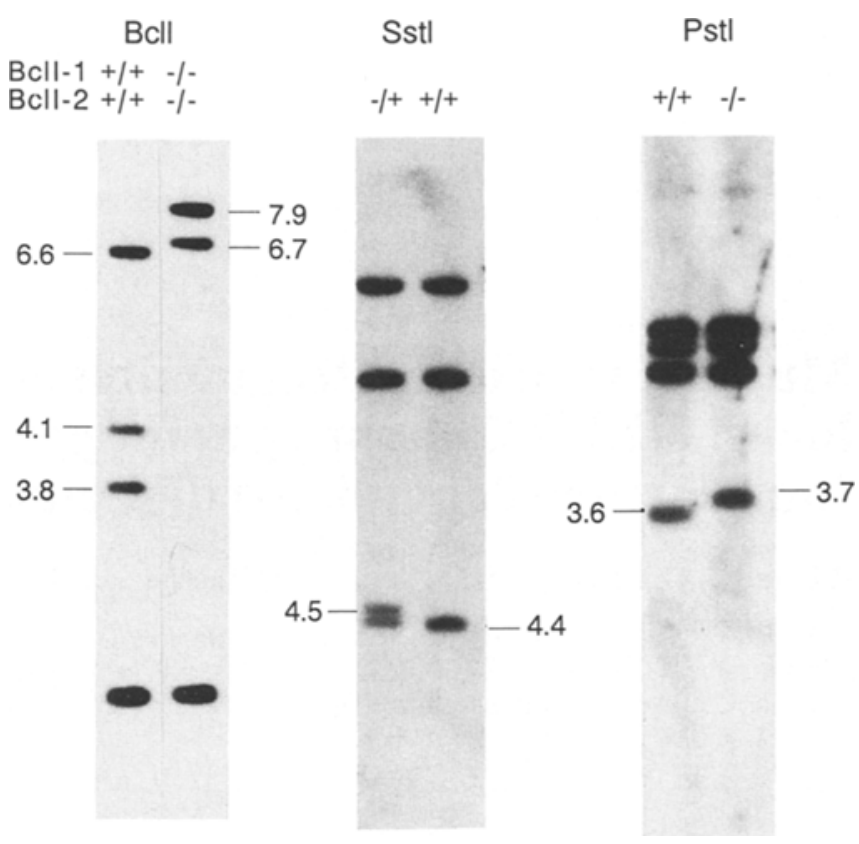

Fig.1. Representative autoradiographs illustrating BclI, SstI and PstI polymorphisms at the GLUT2 locus. The genotype is indicated above each lane

We noted complete concordance for PstI, SstI, BclI-1 and EcoRI-2 RFLP alleles as well as similar size difference (100 base pairs) in 50 unrelated individuals which strongly suggests that these enzymes detect an insertion/deletion type of polymorphism (Table 1). This is in agreement with the conclusion of Matsutani et al. [9], although in that study this polymorphism was not detected with the restriction enzymes PstI, SstI and BclI. Three of the RFLPs, two TaqI (TaqI-1, TaqI-2) and one BclI (BclI-2) RFLPs (scoring the larger allele as - and the smaller allele as + ) gave identical results in 100 individuals (200 chromosomes) although it should be noted that these three RFLPs are clearly dependent on different restriction enzyme sites as they give rise to different sized restriction fragments.

Hence there are five independent polymorphisms at GLUT2 locus, these include EcoRI-1 RFLP, an insertion/deletion polymorphism detected by several restriction enzymes of which we have chosen EcoRI (termed EcoRI-2) for subsequent studies, TaqI-1, TaqI-2 and Bcll-2 RFLPs.

Table 1. Insertion/deletion polymorphism at GLUT2 locus

\begin{tabular}{lll}
\hline $\begin{array}{l}\text { Restriction } \\
\text { enzyme site }\end{array}$ & $\begin{array}{l}\text { Allele size } \\
\text { (kilobase) }\end{array}$ & $\begin{array}{l}\text { Allele frequencies } \\
n=50\end{array}$ \\
\hline EcoRI-2 & 1.9 & 0.09 \\
& 1.8 & 0.91 \\
PstI & 3.7 & 0.09 \\
& 3.6 & 0.91 \\
SstI & 4.5 & 0.09 \\
& 4.4 & 0.91 \\
BclI-1 & 6.7 & 0.09 \\
& 6.6 & 0.91 \\
\hline
\end{tabular}

The frequencies of the alleles for these restriction enzymes were determined in the same 50 non-diabetic subjects 
Table 2. Restriction fragment length polymorphism allele frequencies in Type 2 (non-insulin-dependent) diabetic subjects and nondiabetic control subjects

\begin{tabular}{|c|c|c|c|}
\hline \multirow{2}{*}{$\begin{array}{l}\text { Restriction } \\
\text { enzyme site }\end{array}$} & \multirow{2}{*}{$\begin{array}{l}\text { Allele size } \\
\text { (kilobase) }\end{array}$} & \multicolumn{2}{|c|}{ Allele frequencies } \\
\hline & & $\begin{array}{l}\text { Non-diabetic } \\
\text { subjects }\end{array}$ & $\begin{array}{l}\text { Type } 2 \text { diabetic } \\
\text { subjects }\end{array}$ \\
\hline EcoRI-1 & $\begin{array}{l}5.6 \\
3.4\end{array}$ & $\begin{array}{l}0.84(50) \\
0.16\end{array}$ & $\begin{array}{l}0.86(70) \\
0.14\end{array}$ \\
\hline EcoRI-2 & $\begin{array}{l}1.9 \\
1.8\end{array}$ & $\begin{array}{l}0.09(50) \\
0.91\end{array}$ & $\begin{array}{l}0.09(70) \\
0.91\end{array}$ \\
\hline TaqI-1 & $\begin{array}{l}23 \\
14\end{array}$ & $\begin{array}{l}0.14(50) \\
0.86\end{array}$ & $\begin{array}{l}0.13(56) \\
0.87\end{array}$ \\
\hline TaqI-2 & $\begin{array}{l}7.5 \\
3.9,2.9\end{array}$ & $\begin{array}{l}0.14(50) \\
0.86\end{array}$ & $\begin{array}{l}0.13(56) \\
0.87\end{array}$ \\
\hline $\mathrm{BclI}-2$ & $\begin{array}{l}7.9 \\
4.1,3.8\end{array}$ & $\begin{array}{l}0.14(50) \\
0.86\end{array}$ & $\begin{array}{l}0.13(56) \\
0.87\end{array}$ \\
\hline
\end{tabular}

Figures in parentheses indicate number of individuals studied

\section{Allelic frequencies in Type 2 diabetic subjects and non-diabetic control subjects}

Allelic frequencies were determined at five independent polymorphic sites described by restriction enzymes EcoRI (two RFLPs EcoRI-1 and EcoRI-2), TaqI (two RFLPs TaqI-1 and TaqI-2) and BclI (BslI-2). A comparison of the allele frequencies at each RFLP between the Type 2 diabetic subjects and non-diabetic control subjects shows no significant difference between the two groups (Table 2).

\section{Linkage disequilibrium between restriction site polymorphisms}

The two TaqI RFLPs (TaqI-1 and TaqI-2) and one of the $\mathrm{BclI}(\mathrm{BclI}-2)$ RFLPs are three independent polymorphisms due to different band sizes but are in tight linkage disequilibrium since we did not see any recombination in 200 chromosomes studied at all three sites. Pairwise haplotypes were therefore examined at three RFLPs (EcoRI-1, EcoRI-2, TaqI-1), from unrelated individuals to assess the degree of random association between these sites. The haplotype for a pair of RFLPs could be determined when individuals were either homozygous at both RFLPs or heterozygous at only one. The observed haplotype number for each pair of RFLPs were compared with expected haplotype number, which was predicted from the number of haplotypes available for each pair (Table 3). Evaluation of this pairwise analysis showed random association between the pairs EcoRI-1/EcoRI-2, and EcoRI-1/TaqI-1 and non-random association in a pair EcoRI-2/TaqI-1. The degree of non-random association between a pair of loci was also assessed by the standardized disequilibrium statistic $\Delta$. The values for $\Delta$ were not significantly different from 0 in pairs EcoRI-1/Eco RI-2, and EcoRI-1/TaqI-1 ( $p>0.1)$, however the $\Delta$ values were significantly different from 0 for pair EcoRI-2/Taq I-1 $(p<0.001)$. This finding and the fact that three sites TaqI-1, TaqI-2 and BclI-2 are in tight linkage disequilibrium suggest that EcoRI-2, TaqI-1, TaqI-2 and BclI-2 sites are randomised in relation to the EcoRI-1 polymorphism but are themselves in linkage disequilibrium.

\section{Haplotype frequencies in Type 2 diabetic subjects and non-diabetic control subjects}

Extended haplotypes were constructed at the five polymorphic sites (EcoRI-1, EcoRI-2, TaqI-1, TaqI-2 and BclI-2) in 100 diabetic alleles and 100 non-diabetic control alleles. The latter two polymorphic sites do not give extra information in our population but we have included these sites in the haplotype construction since this may not be the case in other populations. For instance in American blacks the two TaqI RFLPs are not so tightly linked [9]. Construction of haplotypes was based first on individuals homozygous at all sites or heterozygous at only one site. For 100 alleles in diabetic subjects and 100 alleles in non-diabetic control subjects examined at five sites, extended haplotypes could be determined on 84 diabetic alleles and 79 non-diabetic control alleles, where individuals were homozygous at all five sites or heterozygous at only one. One haplotype $(-++++)$ was predominant occurring in $75 \%$ of the chromosomes studied and therefore, for individuals in whom the haplotypes could not be determined in the above fashion we were able to assign in each individual a common haplotype $(-++++)$. Therefore, the haplotype on the other chromosome was assigned by linkage of the remaining sites. Five haplotypes were found at the GLUT2 locus including the very common haplotype ($++++)$, two relatively common haplotypes $(-\ldots$ - and +++++$)$ and two rare haplotypes $(-+---$ and ++---$)$. The frequencies of each haplotype for the diabetic and non-diabetic groups were compared. The

Table 3. Pairwise associations

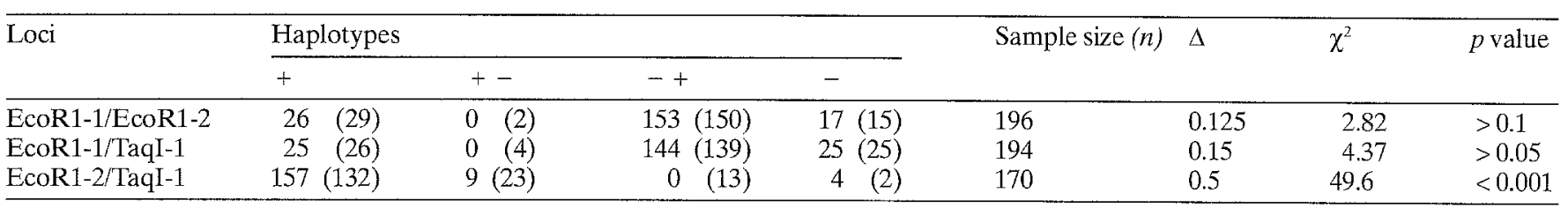

Observed haplotypes were constructed for each pair of RFLPs, expected numbers in parentheses were calculated from the frequencies in Table 2, and the number of haplotypes $(n)$ available for each pair. The disequilibrium statistic $\Delta$ is a measure of the non-random associ- ation of two sites with a value of 0 indicating random association and \pm 1 indicating linkage disequilibrium. Calculated $\Delta$ values are used to test the null hypothesis of linkage disequilibrium $(\Delta=0)$ using $n \Delta^{2}$ $\left(n=\right.$ sample size) as a $\chi^{2}$ variable with 1 degree of freedom 
Table 4. Comparison of haplotypes between non-diabetic subjects and those with Type 2 (non-insulin-dependent) diabetes

\begin{tabular}{|c|c|c|c|c|c|c|c|c|}
\hline \multirow[t]{2}{*}{ Haplotype } & \multirow[t]{2}{*}{ E1, } & \multirow[t]{2}{*}{$\mathrm{E} 2$} & \multirow[t]{2}{*}{$\mathrm{T} 1$} & \multirow[t]{2}{*}{$\mathrm{T} 2$} & \multirow[t]{2}{*}{ B1 } & \multirow[t]{2}{*}{ Expected frequency } & \multicolumn{2}{|c|}{ Observed frequencies } \\
\hline & & & & & & & $\begin{array}{l}\text { Non-diabetic } \\
\text { subjects }\end{array}$ & $\begin{array}{l}\text { Type } 2 \text { diabetic } \\
\text { subjects }\end{array}$ \\
\hline $\mathrm{A}$ & - & + & + & + & + & 0.66 & $0.74(74)$ & $0.78(78)$ \\
\hline $\mathrm{B}$ & - & - & - & - & - & 0.01 & $0.09 \quad(9)$ & $0.10(10)$ \\
\hline $\mathrm{C}$ & + & + & + & + & + & 0.13 & $0.12(12)$ & 0.09 (9) \\
\hline D & - & + & - & - & - & 0.10 & $0.05 \quad(5)$ & $0.02 \quad(2)$ \\
\hline$E$ & + & + & - & - & - & 0.02 & $(0)$ & $0.01 \quad(1)$ \\
\hline
\end{tabular}

E1, E2, T1, T2 and B2 represent EcoRI-1, EcoRI-2, TaqI-1, TaqI-2 and Bcll-2 restriction fragment length polymorphisms (RFLPs) respectively. Values in parentheses are the observed number of chromosomes. Expected frequencies calculated assuming random associations of the five restriction fragment length polymorphisms, and observed frequencies differed significantly $\left(\chi^{2}=10.86, d f=4\right.$,

frequencies of haplotypes did not differ between the two groups $\left(\chi^{2}=2.87, d f=4, p>0.5\right.$ ) (Table 4 ).

To further assess the degree of linkage disequilibrium between these sites, the observed and expected haplotype frequencies were compared in the non-diabetic control group. The observed haplotype frequencies differed $\left(\chi^{2}=10.86, d f=4, p<0.02\right)$ from that predicted by simple chi-squared analysis as expected from the linkage disequilibrium between the four sites (EcoRI-2, TaqI-1, TaqI-2 and BclI-2).

The heterozygosity rates at the GLUT2 locus using the haplotypes were compared in the non-diabetic control group and Type 2 diabetic group. A common deletion of the entire GLUT 2 gene would be manifested as an apparent reduction in the heterozygosity rate for GLUT 2 polymorphisms in the Type 2 diabetic group. The observed heterozygosity was 0.40 for the Type 2 diabetic subjects and 0.50 for the non-diabetic control subjects. Chi-squared analysis showed no significant difference in the heterozygosity rates at the GLUT 2 haplotypes between the Type 2 diabetic and non-diabetic control groups $\left(\chi^{2}=1.44, d f=1\right.$, $p>0.1)$. Thus providing no evidence of a common deletion of the GLUT2 gene in the Type 2 diabetic group. A partial gene deletion may have been expected to result in abnormal variant bands but none were observed.

\section{Discussion}

GLUT2 is the best candidate gene for Type 2 diabetes, of the four well-characterised glucose transporter genes, since the gene is expressed in both the liver and Beta cells of the pancreas. We have found a series of DNA polymorphisms and constructed GLUT 2 haplotypes to enable the present examination of the association between GLUT2 RFLPs and haplotypes, and Type 2 diabetes, and to facilitate future investigations at this locus.

In marked contrast to the findings of Matsutani et al. [9], we report here the presence of many DNA polymorphisms at GLUT 2 locus in a white Caucasian population. The lack of polymorphisms noted by Matsutani et al. in their white individuals could presumably be best explained by the small numbers studied. However, it now seems likely that since the locus is polymorphic in both $p<0.02)$. However, comparison of observed haplotype frequencies between non-diabetic subjects and Type 2 diabetic subjects did not differ $\left(\chi^{2}=2.87, d f=4, p>0.5\right)$. The order of the five restriction sites as shown may not represent the relative physical positions of these sites at the GLUT2 locus

blacks from the USA and British white subjects that many if not all populations can be studied for diabetic disease association with GLUT 2 markers and also by family linkage studies. Approximately half of the individuals in a Caucasian population will be informative at the GLUT2 locus making genetic studies of Type 2 diabetes feasible. This proportion would have been higher if any of the five independent polymorphic sites had two relatively common alleles, rather than a common and a rare allele. This newly determined GLUT2 haplotype should also be of value for the mapping studies of chromosome 3 .

The relationship between the restriction sites is complex since tight linkage disequilibrium is observed between four sites (TaqI-1, TaqI-2, Bcll-2 and EcoRI-2 sites) but not with the EcoRI-1 site and all other sites. There may be a hot spot for recombination between EcoRI-1 site and other RFLP sites but clearly further studies including the physical mapping of the whole region are needed for this question to be resolved. The relatively low number of observed haplotypes (five) in contrast to the theoretical number of $32\left(2^{5}\right)$ is also a reflection of the linkage disequilibrium between the restriction enzyme sites.

By analogy with other well-characterised genetic diseases, if a common mutation was present in the GLUT2 gene then it would be expected to be in linkage disequilibrium with a particular haplotype thereby disturbing the haplotype frequencies in the diabetic group. However, there were no significant differences in the frequencies of GLUT2 RFLPs or haplotypes between the Type 2 diabetic subjects and non-diabetic control subjects. This finding clearly does not exclude rare GLUT2 mutations being the cause of diabetes in some patients. However, it does make it very unlikely that there is a single major mutation at this locus resulting in Type 2 diabetes.

Acknowledgement. This study was supported by the Medical Research Council.

\section{References}

1. Bell GI (1991) Molecular defects in diabetes mellitus. Diabetes 40: $413-422$

2. Fukumoto H, Seino S, Imura $H$ et al. (1988) Sequence, tissue distribution and chromosomal localisation of mRNA encoding a 
human glucose transporter-like protein. Proc Nat Acad Sci USA 85: $5434-5438$

3. Kayano T, Fukumoto H, Eddy RL et al. (1988) Evidence for a family of human glucose transporter-like proteins. J Biol Chem 263: 15245-15248

4. Permutt MA, Koranyi L, Keller K et al. (1989) Cloning and functional expression of a human pancreatic islet glucose-transporter cDNA. Proc Nat Acad Sci USA 86: 8688-8692

5. Mueckler M (1990) Family of glucose transporter genes: implications for glucose homeostasis and diabetes. Diabetes 39:6-11

6. Orkin SH, Kazazian HH, Antonarakis SE et al. (1982) Linkage of beta-thalassaemia mutations and beta-globin gene polymorphisms with DNA polymorphisms in human beta-globin gene cluster. Nature 296: 627-631

7. Estivill X, Scambler PJ, Wainsworth BJ et al. (1987) Patterns of polymorphisms and genetic linkage disequilibrium for cystic fibrosis. Genomics 1: 257-263

8. DiLella AG, Marvit J, Brayton K, Woo SL (1987) An amino-acid substitution involved in phenylketonuria is in linkage disequilibrium with DNA haplotype 2. Nature 327: 333-336

9. Matsutani A, Koranyi L, Cox N, Permutt A (1991) Polymorphisms of GLUT2 and GLUT 4 genes. Diabetes 39: 1534-1542

10. UK Prospective Study of Therapies of Maturity Onset Diabetes. 1. Effect of diet, sulphonylurea, insulin or biguanide therapy on fasting plasma glucose and body weight over one year. Multicentre study (1983). Diabetologia 24: 404-411
11. Maniatis T, Fritsch EF, Sambrook J (1982) "Molecular cloning: a laboratory Manual". Cold Spring Harbour Laboratory, Cold Spring Harbour NY

12. Southern EM (1975) Detection of specific sequences among DNA fragments seperated by gel electrophoresis. J Mol Biol 98: 503-517

13. Feinberg AP, Vogelstein B (1983) A technique for radiolabeling DNA restriction endonuclease fragments to high specific activity. Anal Biochem 132: 6-13

14. Botstein D, White RL, Skolnick M et al. (1980) Construction of a genetic linkage map in man using restriction fragment length polymorphisms. Am J Hum Genet 32: 314-331

15. Patel P, Bell GI, Turner RC, Wainscoat JS (1990) Two EcoRI RFLPS at the GLUT 2 locus. Nucleic Acids Res 18: 4956

Received: 28 May 1991

and in revised form: 14 August 1991

Dr. J.S. Wainscoat

Department of Haematology

John Radcliffe Hospital

Headington

Oxford OX3 9DU

UK 